\title{
Treatment of Familial Hypercholesterolemia with Intracranial Xanthoma: Case Report
}

\author{
XiaoBo Kou, MS, LunXin Liu, MD and LiangXue Zhou, MD* \\ Department of Neurosurgery, West China Hospital, Sichuan University, China
}

*Corresponding author: Liang Xue Zhou, Department of Neurosurgery, West China Hospital, Sichuan University, 610041, Chengdu, China

\begin{abstract}
Intracranial xanthoma is a rare benign intracranial tumor. It often occurs in patients with hyperlipidemia. Intracranial xanthomas grow slowly, and clinical symptoms only appear when the mass compresses the surrounding tissues, so early diagnosis of the disease is difficult.
\end{abstract}

\section{Case Report}

A 25-year-old female complained of right-sided facial paralysis and hearing loss for 4 years, and an intracranial mass was found for 1 week. The patient had a history of $\mathrm{FH}$ and excision of the left elbow mass; positive sign: The right eye is incompletely closed, the right frontal lines and nasolabial fold become shallow, right ear hearing loss, multiple masses are seen in the skin of the right popliteal fossa, sacral caudal (Figure 1a), and right elbow; MRI showed: Right middle posterior skull base mixed density mass; Focal bone destruction (Figure 1b); cholesterol (TC): $14.9 \mathrm{mmol} / \mathrm{L}$, low-density lipoprotein (L-DL) $12.87 \mathrm{mmol} / \mathrm{L}$, After admission, ezetimibe was taken orally to reduce blood lipid. All tumors were removed by retrosigmoid sinus approach under electrophysiological monitoring. Postoperative pathological report: Xanthoma (Figure 1c).

\section{Discussion}

The formation of xanthoma may be due to the phagocytosis of a large number of lipid tissue cells and macrophages. According to whether companion has hyperlipoproteinemia, xanthoma cent hyperlipoproteinemia xanthoma, and other xanthomas two kinds [1]. We present a rare case of $\mathrm{FH}$ complicated with intracranial xanthoma.

The pathogenesis of xanthoma is still controversial. There are currently two theories about the formation mechanism of xanthomas. The first theory is that local trauma or bleeding causes lipids to enter peripheral tissues from blood vessels, causing inflammation of macrophages and fibroblasts; the second theory is those blood lipids are elevated [2]. May cause undifferentiated mesenchymal cells to produce an inflammatory response and accumulate phagocytes [3].

It has been reported in the literature that intracranial xanthomas mostly occur in the temporal occipital region [4]. The MR manifestations: T1 and T2 mixed signals, with flaky fat signal shadows, which are distinguished from diseases such as lipomas, cholesteatoma, and skull tumors [5]. Small xanthomas may have no clinical manifestations when there is no pressure on the surrounding. Imaging examination can help us make an early diagnosis and determine the range of lesions and their adjacent relationships [6].

Xanthoma is a rare benign intracranial tumor, which needs to be differentiated from meningioma, cholesteatoma, lipoma, and other intracranial tumors. Early detection of intracranial xanthomas and drug treatment can make the tumor shrink or even disappear. For xanthomas with clinical manifestations, complete or partial resection of the tumor is required to improve symptoms, and drugs are given for etiological treatment to prevent recurrence after surgery. The future of gene therapy is worth looking forward to, and it may solve this problem fundamentally. 


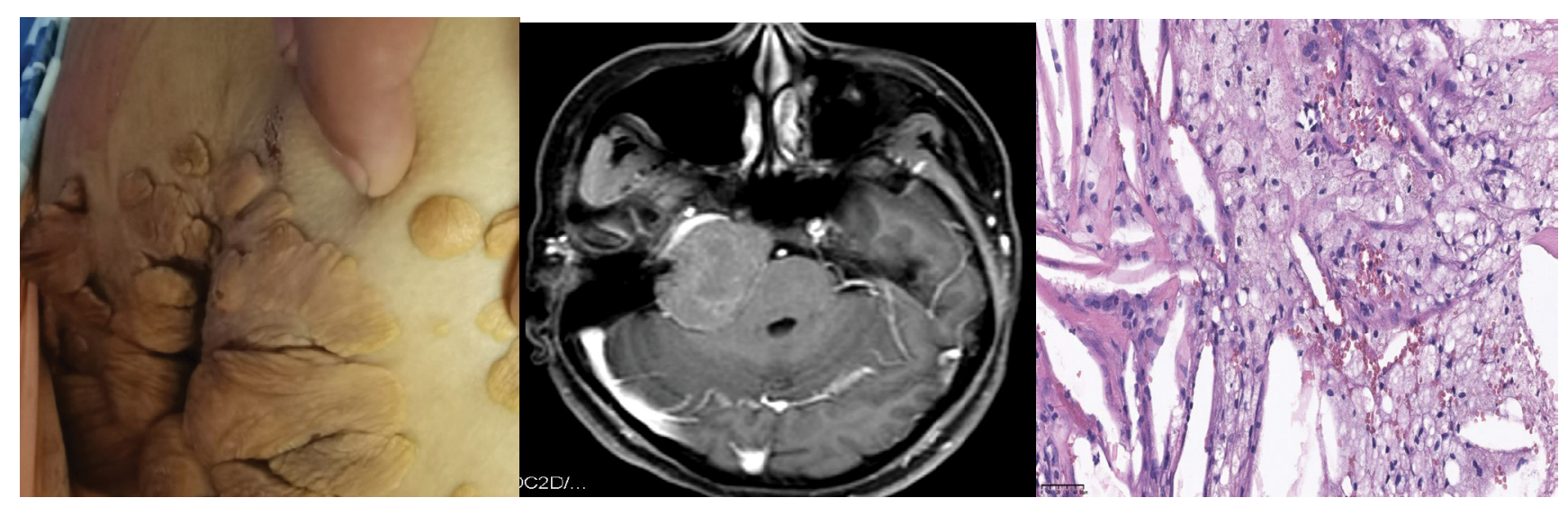

Figure 1: a) Xanthomas on the skin of the sacrococcygeal; b) MRI showed the skull base has long T1 and long T2 lesions on the right side of the middle straddle, with flair showing mixed signals; local bone destruction in the lesion; c) Fibrous tissue hyperplasia with abundant cholesterol fissures, Foam cell aggregation with necrosis and calcification $(\times 40)$.

\section{References}

1. Dung PTV, Son TT, Thuy TTH, Chien VH, Duy TT, et al. (2021) Surgical treatment of multiple large tuberous xanthomas in familial hypercholesterolemia: A case report. Int J Surg Case Rep 89: 106596.

2. Zhao C, Kong M, Cao L, Zhang Q, Fang Y, et al. (2016) Multiple large xanthomas: A case report. Oncol Lett 12: 4327-4332.

3. Aljenedil S, Ruel I, Watters K, Genest J (2018) Severe xanthomatosis in heterozygous familial hypercholesterolemia. J Clin Lipidol 12: 872-877.
4. Asano K, Sato J, Matsuda N, Ohkuma H (2012) A rare case of primary bone xanthoma of the clivus. Brain Tumor Pathol 29: $123-128$.

5. Gonzalez-Garcia L, Asenjo-Garcia B, Bautista-Ojeda MD, Dominguez-Paez M, Romero-Moreno L, et al. (2015) Endoscopic endonasal resection of clival xanthoma: Case report and literature review. Neurosurg Rev 38: 765-769.

6. Meng C, Qiu Q, Su X (2011) A case report of FH combined with bilateral temporal bone xanthomas and literature review. Chinese Journal of Otology 9: 426-429. 